Received: 2013.05.22 Accepted: 2013.06.12 Published: 2013.07.10

Authors' Contribution: Study Design A Data Collection B Statistical Analysis C Data Interpretation D Manuscript Preparation E Literature Search F Funds Collection $G$

\section{Cavernous hemangioma of the parietal bone}

1 Department of Neurosurgery, Elazığ Training Research Hospital, Elazığ, Turkey 2 Department of Pathology, Elazı̆̆ Training Research Hospital, Elazığ, Turkey
A 1 Ibrahim Burak Atcı

A 1 Serdal Albayrak

A 1 Nejat Yılmaz

B 1 Necati Uçler

A 1 Emre Durdağ

A 1 Omer Ayden

D 1 Deniz Kara

A 1 Hülya Bitlisli

$A B 2$ Gülçin Cihangiroğlu

\begin{abstract}
Patient: Male, 38
Final Diagnosis:

Symptoms:

Medication:

Clinical Procedure:

Specialty:

Objective:

Background:

Case Report:

Conclusions:

Cavernous hemangioma

Headache • parietal mass

$-$

Neurosurgery

\section{A rare disease}

Bone hemangioma is a vascular hemartoma of bone structures. In general, this pathology is detected on incidentally investigated patients' films. Bone hemangioma is most commonly seen in $4^{\text {th }}$ decade of life and the male/female ratio is $1 / 1.5$. The locations of these lesions are commonly long bones of the vertebral column and the skull.

Primary bone hemangiomas constitute less than $1 \%$ of all bone tumors, and they are seen at $0.2 \%$ in the calvarial region.

Cases with this pathology are seen on incidental radiological evaluations. We report the case of a 38-year-old man with localized headache and a palpable mass in the left parietal region, admitted and operated on after cranial CT and MRI. Pathology investigation revealed a cavernous hemangioma.

We suspected that in our case head trauma may have been the cause of cavernous hemangioma in the calvarial region, because cavernous hemangiomas are rarely located there. Localized headache and minor discomfort can be seen with this pathology. The best treatment for cavernous hemangiomas is the removal of the mass within the limits of safe surgery.
\end{abstract}

Key words: $\quad$ headache $\bullet$ trauma $\bullet$ cavernous hemangioma

Full-text PDF: $\quad$ http://www.amjcaserep.com/download/index/idArt/889388 


\section{Background}

Bone hemangioma is a vascular hemartoma of bone structures. In general, this pathology is detected on incidentally investigated patients' films. Bone hemangioma is most commonly seen in the $4^{\text {th }}$ decade of life and the male/female ratio is $1 / 1.5$ [1]. The locations of these lesions are commonly long bones of the vertebral column and the skull [1].

Primary bone hemangiomas are less than $1 \%$ of all bone tumors, and they are seen at $0.2 \%$ in the calvarial region $[1,2]$. However, these tumors usually located in the parietal and frontal regions $[3,4]$. Traumatic types are rarer than congenital hemangiomas.

They cause swelling in involved skull bones and, rarely, headache due to their bone-expansive features [5]. The granular calcifications ("sunlight view") may be seen on the skull x-ray. Also, these calcifications may be multicentric. Macroscopically, hemangiomas are soft, easily broken, red-blooded tissues.
Cavernous, vascular, endothelial cells forming the epithelial lining and blood elements are observed microscopically.

\section{Case Report}

A 38-year-old man with a left parietal mass and intermittent localized pain was admitted to our clinic. The patient had a history of a motor vehicle injury to the left parietal region 2 years ago. The patient was evaluated with $\mathrm{CT}$, which showed an increase in the left parietal diploë space (Figure 1). After $\mathrm{CT}$, the patient was screened MRI, which showed an expansive lesion in the bone structure (Figure 2). Dural connection and parenchymal compression were not seen on MRI.

The mass was $2 \times 2 \times 2 \mathrm{~cm}$ in size and was excised (Figures 3 and 4). Histopathology of the mass showed fibroconnective tissue containing osseous areas in some places and large blood vessels in the stroma. The histopathology result was reported as cavernous hemangioma (Figures 5 and 6).

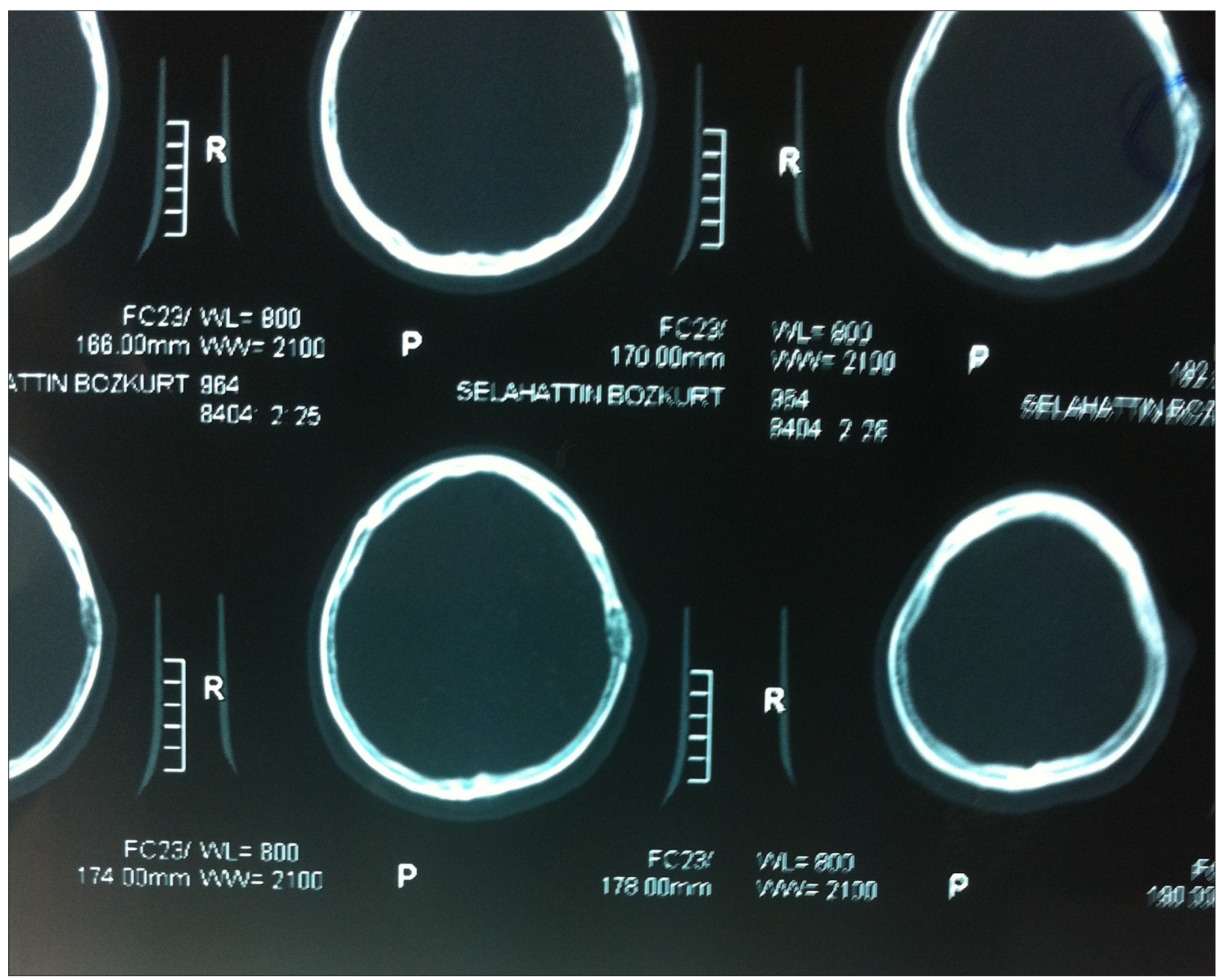

Figure 1. Pre op. cranial CT. 


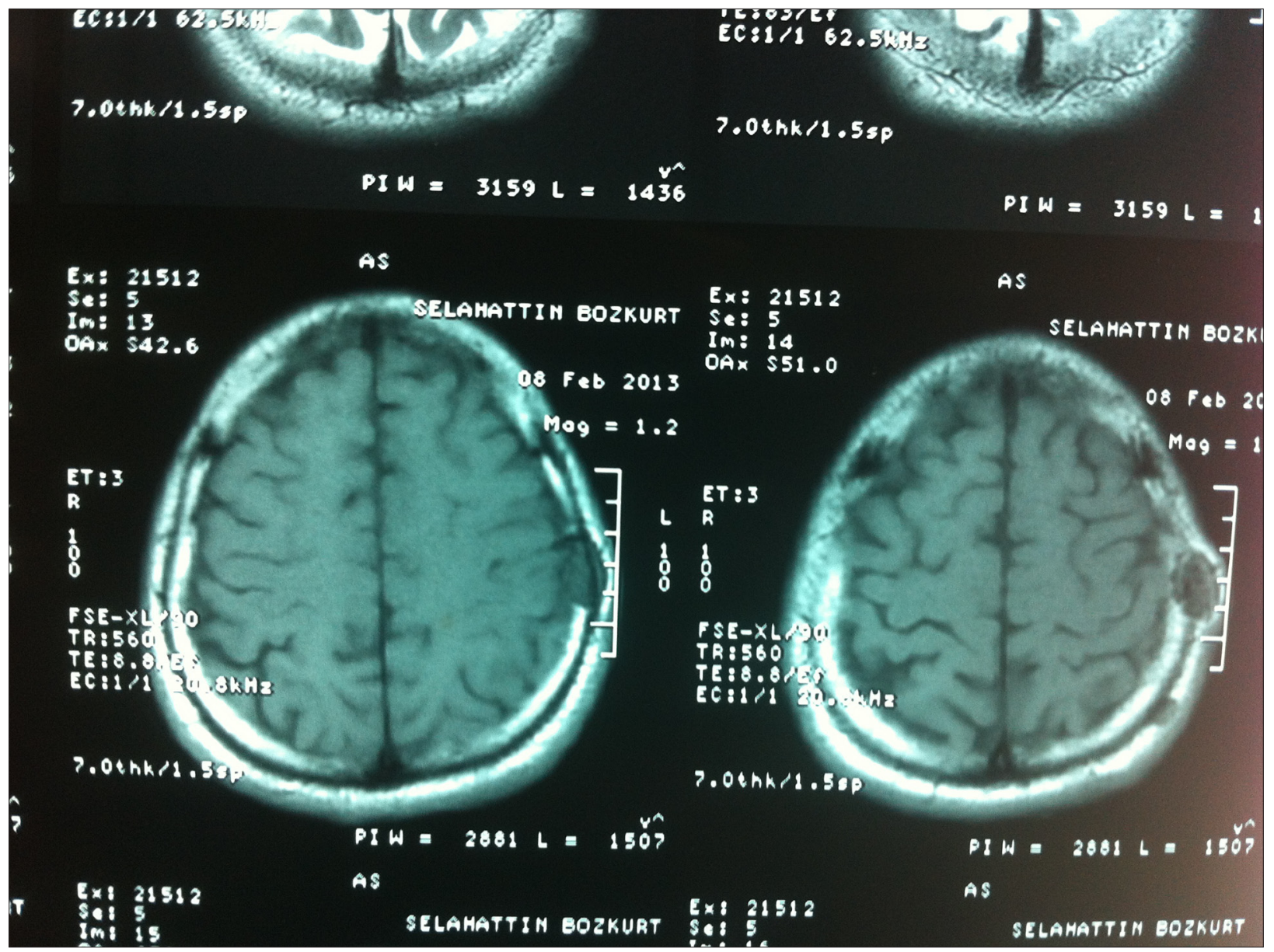

Figure 2. Pre op. cranial MRG.

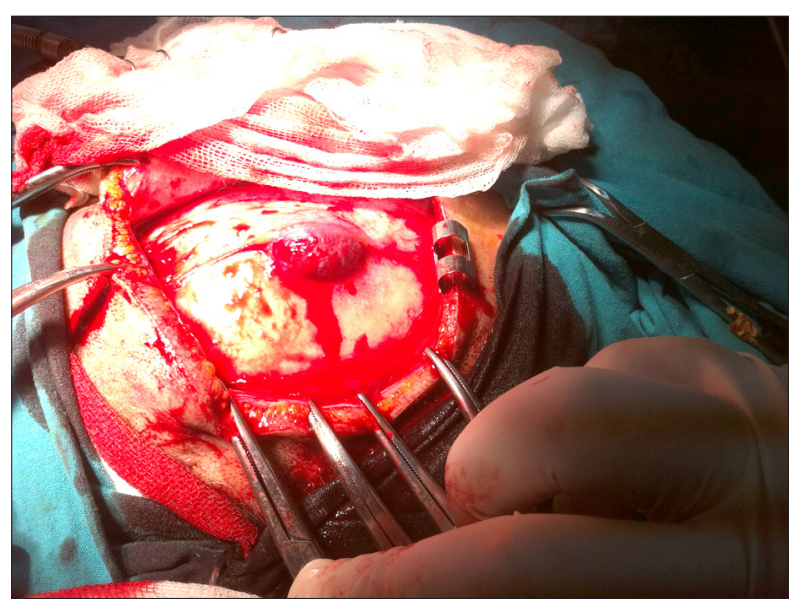

Figure 3. Parietal bone with hemangioma.

\section{Discussion}

Cavernous hemangiomas are often seen in the vertebral column, but are rarely seen in the skull. Intraosseous hemangiomas of the skull constitute $0.2 \%$ of all bone tumors, and are commonly seen in frontal and parietal bones [4-6]. However, occipital,

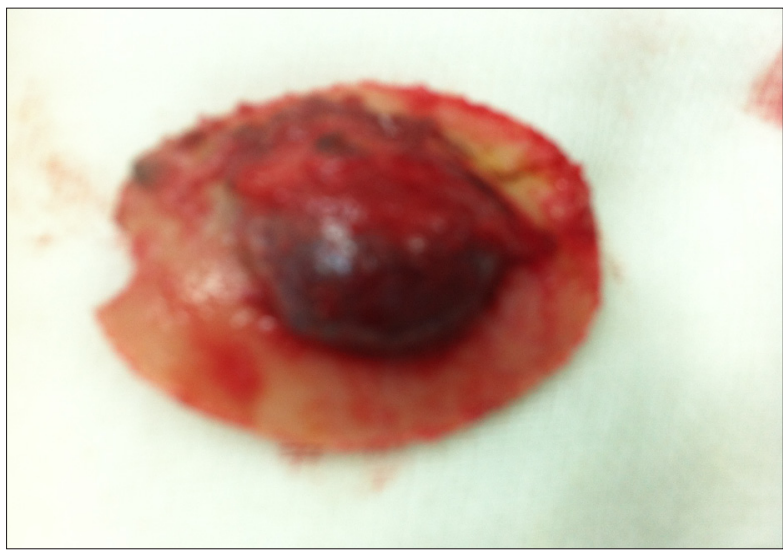

Figure 4. Parital bone craniotomy material.

sphenoid, and temporal bones may be involved [4]. The incidence of these tumors increases in females and in the $2^{\text {nd }}$ and $4^{\text {th }}$ decades of life. Cavernous hemangiomas consist of blood vessels separating fibrous tissues. Most types of calvarial hemangiomas are fed from branches of the external carotid artery, especially from branches of the middle meningeal artery, superficial temporal artery, and posterior occipital artery $[7,8]$. 


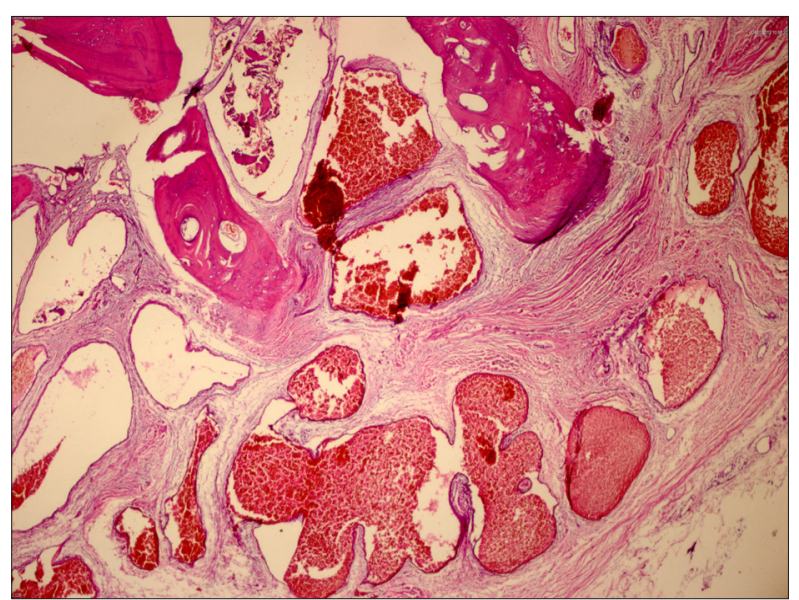

Figure 5. Pathological specimen (hematoxylin and eosin; 200x).

A lytic lesion affecting the outer layer of the skull, without the internal layer, may cause sclerotic margin. Bone spicules extending from center to periphery in the lytic lesion (sunburst pattern or honeycombing) are characteristic for the lesion. However, this finding may be seen in meningioma, osteogenic sarcoma, and osteoblastic metastases. The MRI signal of hemangioma is variable and the hyperintensity of hemangiomas at T1-weighted sequences is an important distinguishing feature for these tumors [1].

Calvarial hemangiomas are generally seen as congenital in the literature. The rates are low after head trauma when compared with congenital forms. The effect of trauma on the development of hemangiomas is unclear [3-7]. It is thought that some growth factors are released after trauma. Our case was a 38-year-old male and had a history of trauma to the parietal bone 2 years ago.

These tumors can be misdiagnosed as a dermoid cyst, a giant cell tumor of bone, multiple myeloma, and metastasis [2]. Preoperative diagnosis of this tumor may be difficult because of its similarity to other bone pathologies. The most useful radiological tool is CT, clearly showing cortical and trabecular structures $[9,10]$. The diagnosis of cavernous hemangiomas is established by histopathology. Hemangiomas consist of 4

\section{References:}

1. Khanam H, Lipper MH, Wolff CL, Lopes MB: Calvarial hemangiomas: report of two cases and review of the literature. Surg Neurol, 2001; 55: 63-67

2. Vernet $\mathrm{O}$, Bernasconi A, Fankhauser H: Cavernous hemangioma of the frontal bone: a case report. Turkish Neurosurgery, 1993; 3: 118-21

3. Dogan S, Kocaeli H, Sahin S et al: Large cavernous hemangioma of the frontal bone: case report. Neurol Med Chir (Tokyo), 2005; 45: 264-67

4. Heckl S, Aschoff A, Kunze S. Cavernomas of the skull: review of the literature 1975-2000. Neurosurg Rev, 2002; 25: 56-62

5. Kang DW, Choi $\mathrm{CH}$ : A case of calvarial hemangioma in cranioplasty site. J Korean Neurosurg Soc, 2009; 46: 484-87

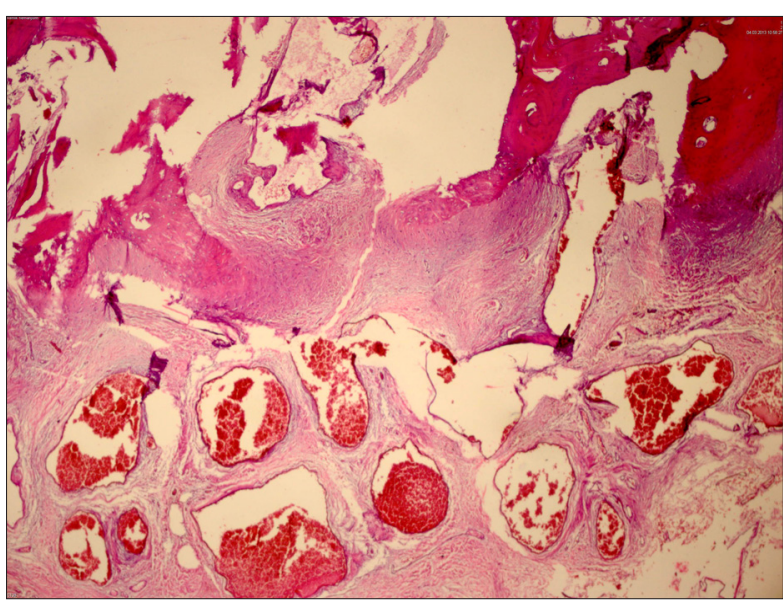

Figure 6. Pathological specimen (hematoxylin and eosin; 200x).

types: cavernous, sclerosing, cellular, and capillary. The most common is cavernous type [6].

Our patient was diagnosed histologically as having cavernous hemangioma.

Hemangiomas are usually symptomatic lesions. Clinical findings include headache, increased intracranial pressure by parenchymal compression, cranial nerve deficits, and cosmetic changes [4]. In our case, correction of cosmetic changes and localized pain were the purposes of the surgery. If possible, the aim of surgery should include normal neighboring bones for these tumors.

\section{Conclusions}

As a result, we suggest that head trauma may be the cause of cavernous hemangioma in the calvarial region, as in our case, because cavernous hemangiomas are rarely seen in the calvarial region. Localized headache and minor discomfort can be seen with this pathology. The best treatment for cavernous hemangiomas is the removal of the mass within the limits of safe surgery.

6. Valentini V, Nicolai G, Lore B et al: Intraosseous hemangiomas. J Craniofac Surgery, 2008; 19: 1459-64

7. Pastore FS, De Caro GM, Faiola A et al: Cavernous hemangioma of theparietal bone. Case report and review of the literature. Neuro Chirurgie, 1999; 45: 312-15

8. Bastug D, Ortiz O, Schochet SS: Hemangiomas in thecalvaria: Imagingfindings. Am J Roentgenol, 1995; 164: 683-87

9. Moore SL, Chun JK, Mitre SA, Som PM: Intraosseous hemangioma of the zygoma: CT and MR findings. Am J Neuroradiol, 2001; 22: 1383-85

10. Liu JK, Burger PC, Harnsberger HR et al: Primary intraosseous skull base cavernous hemangioma: case report. Skull Base, 2003; 13: 219-28 